\title{
Augmented Reality-Based Application Design for the Introduction of Rattan Furniture
}

\author{
Elma Tryana ${ }^{1}$, Lili Rusdiana ${ }^{2}$ \\ 1 STMIK Palangkaraya/Teknik Informatika \\ 2 STMIK Palangkaraya/Teknik Informatika
}

\begin{abstract}
Design is one of the important stages in building applications, also in building applications based on augmented reality. Augmented reality can visualize images into $3 D$ forms for rattan furniture objects. This study aims to design applications in the introduction of furniture, so that the introduction of interior furniture is carried out through applications without having to go to furniture sales locations. There are 5 pieces of furniture that are included in the design of augmented reality-based applications, namely tables, chairs, sofas, cabinets, and baskets. Interface design using balsamiq wireframes. The design is also carried out by describing the design description through storyboards. Designing the use of augmented reality through image content on cards that function as markers. The data collection method used to design the application is the method of observation and literature.
\end{abstract}

Keywords: Application; Augmented reality; Balsamiq wireframes; Design; Furniture

corresponding email : fasliiana7@gmail.com

This is an open access article under the CC BY license

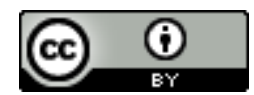

\section{INTRODUCTION}

Perancangan aplikasi sangat diperlukan sebelum aplikasi mulai dibangun. Melalui perancangan, akan terdapat kemungkinan perbaikan atau pengembangan terhadap perancangan yang dilakukan. Termasuk dalam merancang aplikasi berbasis augmented reality. Perancangan dilakukan terhadap aplikasi pada smartphone dengan sistem operasi android. Sehingga diperlukan penggunaan software dalam merancang dan juga mencakup tools perancangan untuk smartphone berbasis android. Tujuan dari penelitian ini yaitu untuk merancang aplikasi dalam mengenalkan furnitur berbahan rotan melalui smartphone sehingga memudahkan dalam pengenalan furnitur kepada masyarakat melalui aplikasi tanpa harus ke lokasi penjualan furnitur. Desain aplikasi terkait media virtual reality dengan menggabungkan hiburan dan pengetahuan sehingga desain mampu memberikan gambaran bahwa aplikasi menginteraksikan antara pengguna dan lingkungan virtual dengan menampilkan keberadaan objek beserta informasinya [1].

Perancangan dalam penelitian ini juga dilakukan agar memudahkan dalam mengembangkan ide untuk aplikasi yang akan dibangun nantinya. Rancangan aplikasi menghasilkan gambaran sebagai panduan dalam membangun aplikasi, sehingga aplikasi yang dibangun lebih terarah dan sesuai dengan tujuan pembangunan aplikasi seperti pada sarana pembelajaran metamorfosis kupu-kupu melalui aplikasi augmented reality [2].

Perancangan dalam penelitian ini menggunakan storyboard untuk perancangan prosesnya, sedangkan penggunaan balsamiq wireframes sebagai tools untuk merancang interface terhadap aplikasi yang akan dibangun nantinya. Perancangan interface diperlukan terhadap pembangunan aplikasi berbasis augmented reality seperti sebagai media promosi penjualan [3]. Perancangan tidak hanya pada interface namun juga pada marker [4]. Perancangan aplikasi menggunakan image content sebagai marker. Perancangan aplikasi augmented reality pada furnitur dalam bentuk katalog dapat dilakukan dengan menggunakan metode single dan multimarker [5]. 
JAST : Journal of Applied Science and Technology

Volume. 02 Number. 01, January 2022

ISSN : 2775-4022

http://jurnal.unissula.ac.id/index.php/JAST

\section{LITERATURE REVIEW}

Augmented Reality (AR) memiliki potensi yang sangat besar diberbagai bidang seperti pendidikan, budaya, usaha, bahkan militer. Sehingga augmented reality juga berguna untuk masyarakat luas. Di dunia pendidikan sendiri, pengenalan tata surya menggunakan augmented reality memiliki pengaruh untuk mengenalkan tata surya. Melalui aplikasi augmented reality, objek 3 Dimensi yang ditampilkan dapat dijadikan sebuah alat peraga virtual untuk menggantikan alat peraga fisik yang tidak ada [6]. Teknologi augmented reality juga dapat dimanfaatkan untuk desain interior atau pemilihan alat dalam institusi pendidikan seperti sekolah, khususnya pada laboratorium sekolah [7], perancangan aplikasi menggunakan UML (Unified Modelling Language). Selain menggunakan UML, perancangan juga dapat dilkaukan dengan menggunakan storyboard sebagai penggambaran perancangan proses, seperti pengenalan alat transportasi darat dengan menggunakan augmented reality yang menggunakan storyboard sebagai perancangan proses dari aplikasi [8]

UML juga digunakan sebagai salah satu cara dalam perancangan, yang menentukan dan memvisualisasi dari aplikasi augmented reality untuk pengenalan mobil Honda [9]. Selain penggunaan aplikasi augmented reality mengenai mobil yang umum digunakan masyarakat. Pengenalan mobil militer pun dapat dilakukan dengan aplikasi augmented reality, perancangan interface dilakukan dengan menggunakan figma [10]

Di bidang budaya juga teknnologi augmented reality dapat dirancang menggunakan katalog untuk menampilkan objek artepak warisan budaya [11]. Tak hanya di bidang budaya, di dunia usaha pun augmented reality merambah untuk keperluan belanja yakni untuk keperluan belanja furnitur secara online [12] dan memvisualisasikan katalog penjualan furnitur [13]. Selain itu, untuk meningkatkan penjualan furnitur, juga dapat dilakukan dengan augmented reality untuk mengatur tata letak furnitur di dalam ruangan [14] [15] [16].

Penggunaan teknologi augmented reality untuk pengenalan furnitur tidak harus menguntungkan seperti penjualan. Namun dapat dilakukan untuk budidaya rotan melalui pengenalan furnitur berbahan rotan seperti pada penelitian ini.

\section{RESEARCH METHOD}

Perancangan yang dilakukan yakni perancangan storyboard dan perancangan interface. Perancangan storyboard ditampilkan dalam bentuk tabel seperti pada Tabel 1 sampai dengan Tabel 5. Sementara untuk perancangan interface ditampilkan dalam bentuk gambar yakni dari Gambar 1 sampai dengan Gambar 4.

a. Perancangan Storyboard aplikasi

Perancangan proses yang digunakan dalam perancangan aplikasi menggunakan storyboard, seperti pada Tabel 1.

Tabel 1. Storyboard aplikasi

\begin{tabular}{|c|c|l|l|l|}
\hline Scene & Sequence & \multicolumn{1}{|c|}{ Outline } & \multicolumn{1}{|c|}{ Description } & \multicolumn{1}{|c|}{ Camera subject } \\
\hline 1 & 1 & Splash screen & Tampilan pembukaan pada aplikasi & - \\
\hline 2 & 2 & Menu utama & $\begin{array}{l}\text { Menampilkan daftar menu yang terdiri dari } \\
\text { mulai, tentang, dan keluar }\end{array}$ & - \\
\hline 3 & 3 & $\begin{array}{l}\text { Memulai AR } \\
\text { kamera }\end{array}$ & $\begin{array}{l}\text { Menampilkan daftar menu furnitur yang } \\
\text { terdiri dari meja, kursi, sofa, lemari, keranjang. }\end{array}$ & - \\
\hline 4 & 4 & Meja & $\begin{array}{l}\text { Memulai pembacaan marker pada image } \\
\text { content untuk menampilkan animasi }\end{array}$ & $\begin{array}{l}\text { Menampilkan objek berupa } \\
\text { animasi furnitur 3D }\end{array}$ \\
\hline 5 & 5 & Kursi & $\begin{array}{l}\text { Memulai pembacaan marker pada image } \\
\text { content untuk menampilkan animasi }\end{array}$ & $\begin{array}{l}\text { Menampilkan objek berupa } \\
\text { animasi furnitur 3D }\end{array}$ \\
\hline 6 & 6 & Sofa & $\begin{array}{l}\text { Memulai pembacaan marker pada image } \\
\text { content untuk menampilkan animasi }\end{array}$ & $\begin{array}{l}\text { Menampilkan objek berupa } \\
\text { animasi furnitur 3D }\end{array}$ \\
\hline 7 & 7 & Lemari & $\begin{array}{l}\text { Memulai pembacaan marker pada image } \\
\text { content untuk menampilkan animasi }\end{array}$ & $\begin{array}{l}\text { Menampilkan objek berupa } \\
\text { animasi furnitur 3D }\end{array}$ \\
\hline 8 & 8 & Keranjang & $\begin{array}{l}\text { Memulai pembacaan marker pada image } \\
\text { content untuk menampilkan animasi }\end{array}$ & $\begin{array}{l}\text { Menampilkan objek berupa } \\
\text { animasi furnitur 3D }\end{array}$ \\
\hline 9 & 9 & Tentang & Penjelasan mengenai rotan & - \\
\hline 10 & 10 & Refresh & Memuat kembali gerakan objek & - \\
\hline 11 & 11 & Unduh Marker & Mengunduh marker pada google drive & - \\
\hline 12 & 12 & Keluar & Keluar dari aplikasi & - \\
\hline
\end{tabular}

b. Perancangan Storyboard pada scene splash screen

Storyboard Scene dari Splash Screen yang tampil pada saat aplikasi dimulai yaitu seperti pada Tabel 2. 
JAST : Journal of Applied Science and Technology

Volume. 02 Number. 01, January 2022

ISSN : 2775-4022

http://jurnal.unissula.ac.id/index.php/JAST

Tabel 2. Storyboard pada scene splash screen

\begin{tabular}{|l|c|c|}
\hline \multicolumn{1}{|c|}{ Visual } & Sketsa & Audio \\
\hline $\begin{array}{l}\text { Splash screen tersebut disertai dengan splash screen default } \\
\text { dari Unity 3D dan aplikasi yang dibuat oleh penulis. }\end{array}$ & $\begin{array}{c}\text { FURNITUR ROTAN } \\
\text { AUGMENTED REALITY }\end{array}$ & $\ldots . . . .$. Mp3 \\
\cline { 2 - 3 } & & \\
\end{tabular}

c. Perancangan Storyboard pada menu utama

Storyboard menu utama, pada tampilan ini terdapat 3 pilihan menu yaitu mulai, tentang dan keluar. Storyboard menu utama ditunjukkan seperti pada Tabel 3.

Tabel 3. Storyboard pada Menu Utama

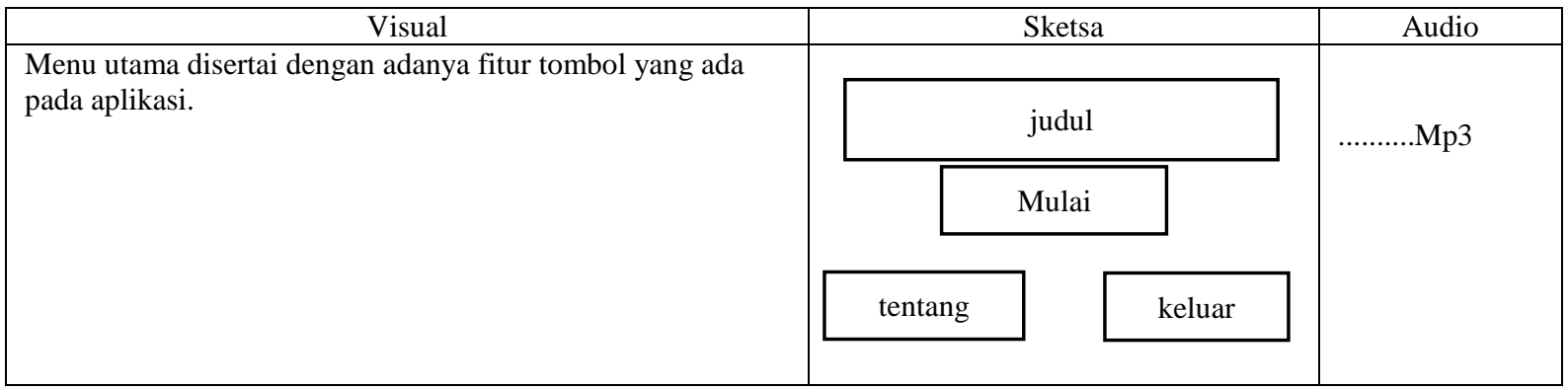

d. Perancangan Storyboard pada menu Tentang

Storyboard pada menu Tentang yang menjelaskan secara singkat mengenai aplikasi, ditunjukkan seperti pada Tabel 4.

Tabel 4. Storyboard pada menu Tentang

\begin{tabular}{|c|c|c|}
\hline Visual & Sketsa & Audio \\
\hline Berisi tentang aplikasi yang dibuat. & $\begin{array}{ll}\text { TENTANG } & \\
\ldots \ldots \ldots \ldots \ldots & \\
\ldots \ldots \ldots \ldots \ldots & \\
\ldots \ldots \ldots \ldots \ldots & \\
& \text { KEMBALI }\end{array}$ & ........Mp3 \\
\hline
\end{tabular}

e. Halaman Augmented Reality

Halaman menu augmented reality yang menampilkan beberapa pilihan furnitur yang akan dilihat melalui aplikasi. Halaman menu augmented reality ditunjukkan seperti pada Tabel 5.

Tabel 5. Storyboard pada menu augmented reality

\begin{tabular}{|c|c|c|c|}
\hline \multirow{5}{*}{$\begin{array}{c}\text { Visual } \\
\text { Menampilkan objek berupa Furniture beserta deskripsinya. }\end{array}$} & \multicolumn{2}{|c|}{ Sketsa } & Audio \\
\hline & Мeja & Kursi & \multirow{4}{*}{..........Mp3 } \\
\hline & \multicolumn{2}{|c|}{ Sofa } & \\
\hline & Lemari & Keranjang & \\
\hline & Kembali & & \\
\hline
\end{tabular}

Perancangan interface yang dilakukan mengunakan balsamiq wireframes untuk menampilkan beberapa rancangan sebagai berikut : 
a. Perancangan Splash Screen

Splash Screen yang ditampilkan yaitu scene yang berfungsi sebagai tampilan awal saat aplikasi dijalankan. Pada scene ini pengguna tidak perlu melakukan klik menu, namun hanya menunggu proses aplikasi menampilkan menu utama. Perancangan splash screen ditunjukkan seperti pada Gambar 1.

\section{FURNITUR ROTAN AUGMENTED REALITY}

Gambar 1. Perancangan splash screen

Setelah tampil Splash Screen maka selanjutnya tampil halaman menu utama.

b. Perancangan Menu Utama

Perancangan menu utama merupakan scene utama agar pengguna dapat memilih menu yang tersedia, yaitu menu mulai, tentang, dan keluar. Perancangan menu utama ditunjukkan seperti pada Gambar 2.

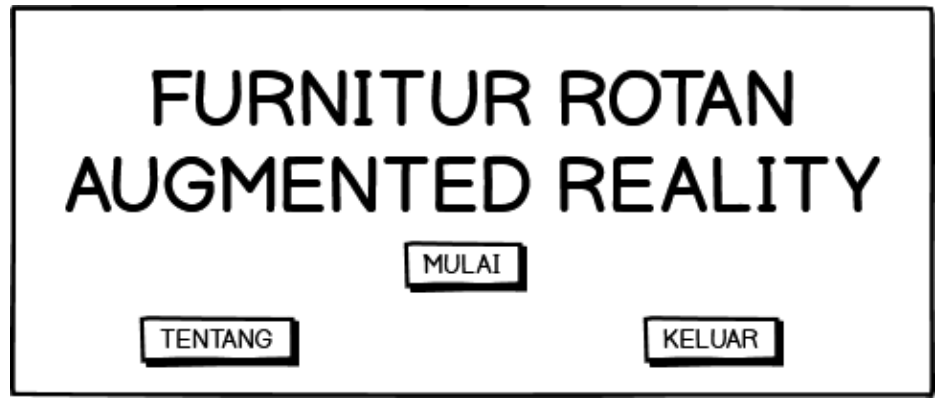

Gambar 2. Perancangan scene menu utama

Dari Gambar 2 menunjukkan masing-masing menu dalam bentuk tombol yang akan menampilkan ke menu lainnya. Seperti menu MULAI, akan menampilkan pilihan tampilan augmented reality terkait penggunaan marker untuk menampilkan hasil 3D. Kemudian menu TENTANG yang akan menampilkan mengenai informasi aplikasi dan menampilkan menu berupa tombol untuk mengunduh marker. Menu terakhir dari halaman menu utama yaitu menu KELUAR, menu ini berfungsi untuk keluar dari aplikasi.

c. Perancangan Halaman Mulai Augmented Reality

Pada halaman ini berisi 5 tombol untuk mengarah ke masing-masing tampilan augmented reality untuk menggunakan marker sehingga menampilkan efek 3D. Perancangan halaman mulai ditunjukkan seperti pada Gambar 3.

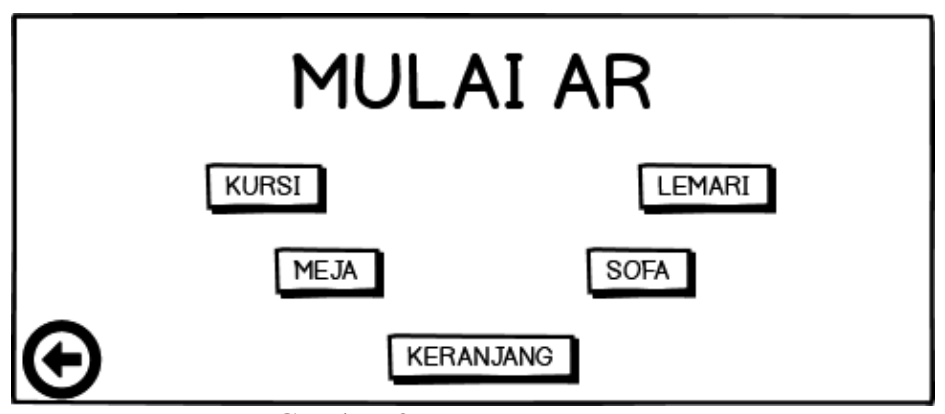

Gambar 3. Perancangan scene tentang 
JAST : Journal of Applied Science and Technology

Volume. 02 Number. 01, January 2022

ISSN : 2775-4022

http://jurnal.unissula.ac.id/index.php/JAST

Masing-masing tombol seperti pada Gambar 3, akan menunjukkan ke fungsi yang berbeda sesuai dengan teks pada tombol tersebut. Sebagai contoh, jika memilih tombol MEJA, kemudian mengaktifkan kamera dan mengarahkan ke marker yang sesuai dengan nama tombol, maka objeknama tombol yaitu objk 3D sebuah meja. Begitu juga dengan tombol KURSI, LEMARI, SOFA, dan KERANJANG. Masing-masing akan menampilkan objek 3D yang sesuai dengan marker yang digunakan.

d. Perancangan Halaman Tentang

Pada halaman tentang ini berisi mengenai deskripsi singkat dari aplikasi yang dibuat. Perancangan halaman tentang ditunjukkan seperti pada Gambar 4.

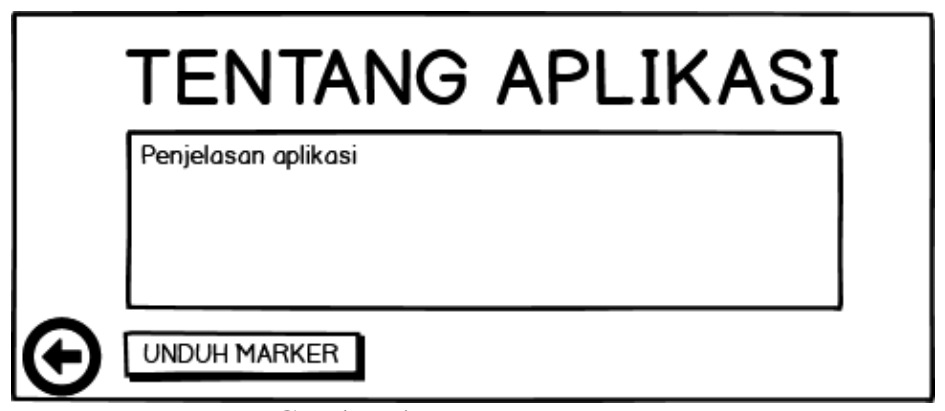

Gambar 4. Perancangan scene tentang

Tahapan yang digunakan dalam pengumpulan data dan selanjutnya digunakan untuk perancangan yaitu sebagai berikut : .

a. Observasi

Observasi yakni pengumpulan data dengan mengamati secara langsung ke pengrajin rotan untuk mengambil data yang dibutuhkan dalam merancang model furnitur. Data tersebut merupakan jenis rotan yang dibutuhkan untuk membuat meja, kursi, sofa, lemari, dan keranjang

b. Studi Pustaka

Melalui studi pustaka, membaca serta mempelajari buku dan jurnal referensi terkait penelitian yang dilakukan yakni tentang perancangan, augmented reality, furnitur dan hal lainnya yang dijadikan acuan sebagai bahan dan informasi untuk digunakan dalam penelitian ini.

\section{RESULT AND ANALYSIST}

Berdasarkan pada perancangan storyboard dan perancangan interface, tampak alur gambaran mulai dari input, proses, dan output yang nantinya dalam dilakukan dalam pembangunan aplikasi. Perancangan storyboard mengambarkan proses mulai dari tampilan awal membuka aplikasi dengan tampilan splash screen hingga keluar dari penggunaan aplikasi dengan fitur menu atau tombol keluar. Perlunya gambaran berupa tombol beberapa pilihan menu yang dapat di pilih untuk menampilkan masing-masing gambar yang dihasilkan agar dapat menampilkan hasil dari proses augmented reality yakni objek 3D.

Penggunaan marker menyesuaikan dengan tombol yang dipilih seperti pada Gambar 3. Jika tombol yang dipilih tidak sesuai dengan marker yang digunakan maka objek 3D tidak akan tampak.

Perlunya perancangan storyboard dan perancangan interface memudahkan untuk membuat alur dan menentukan fungsi dari setiap fitur yang akan digunakan seperti fitur urutan halaman, fitur penggunaan tombol, dan fitur dari proses penampilan objek 3D.

\section{CONCLUSION}

Pengumpulan data dilakukan sebelum memulai rancangan aplikasi berbasis augmented reality, agar data yang diperlukan baik berupa input, proses, maupun output akan jelas tergambar melalui perancangan yang dilakukan. Rancangan aplikasi merupakan hal penting dalam tahapan sebelum membangun aplikasi. Rancangan proses berupa storyboard dan rancangan interface untuk meminimalisir kesalahan dalam membangun aplikasi nantinya. Penentuan perancangan yang matang akan memudahkan dalam pembangunan aplikasi. Balsamiq wireframe sebagai salah satu tools yang digunakan dalam mendukung perancangan interface. 
JAST : Journal of Applied Science and Technology

Volume. 02 Number. 01, January 2022

ISSN : 2775-4022

http://jurnal.unissula.ac.id/index.php/JAST

\section{REFERENCES}

[1] I. P. A. Prayudha, A. A. K. A. C. Wiranatha and I. M. S. Raharja, "Aplikasi Virtual Reality Media Pembelajaran Sistem Tata Surya," MERPATI, vol. 5, no. 2, pp. 72-80, 2017.

[2] F. Ningsih, L. Rusdiana and Rudini, "Analisis dan Desain Aplikasi Pembelajaran Metamorfosis," SINTECH JOURNAL, vol. 2, no. 2, pp. 118-123, 2019.

[3] A. Z. Prabowo, K. I. Satoto and K. T. Martono, "Perancangan dan Implementasi Augmented Reality sebagai Media Promosi Penjualan Perumahan," Jurnal Teknologi dan Sistem Komputer, vol. 3, no. 1, pp. 161-170, 2015.

[4] E. D. Fransiska, T. M. Akhriza and L. A. Primandari, "Implementasi Teknologi Augmented Reality Sebagai Media Pembelajaran Informatif dan Interaktif Untuk Pengenalan Hewan," in Seminar Nasional Sistem Informasi (SENASIF) Fakultas Teknologi Informasi Universitas Merdeka Malang, Malang, 2017.

[5] E. B. Sembiring, Sapriadi and Y. C. Brahmana, "Rancang Bangun dan Analisis Aplikasi Augmented Reality pada Produk Furniture," Jurnal Integrasi, vol. 8, no. 1, pp. 22-28, 2016.

[6] S. D. Y. Kusuma, "Perancangan Aplikasi Augmented Reality Pembelajaran Tata Surya," Jurnal Informatika Universitas Pamulang, vol. 3, no. 1, pp. 33-38, 2018.

[7] D. S. Utomo, I. Arwani and W. S. Wardhono, "Implementasi Mobile Augmented Reality Pada Aplikasi Pemilihan Sarana dan Prasarana Laboratorium Sekolah Menengah Atas," Jurnal Pengembangan Teknologi Informasi dan Ilmu Komputer, vol. 1, no. 3, pp. 224-235, 2013.

[8] S. Febrina, L. Rusdiana and Rosmiati, "Android-Based Augmented Reality in Education Activity for Children," PIKSEL: Penelitian Ilmu Komputer Sistem Embedded and Logic, vol. 8, no. 2, pp. 101-106, 2020.

[9] Andi, G. Hoendarto and Lina, "Perancangan Aplikasi Augmented Reality Pengenalan Mobil Honda Berbasis Android," MASITIKA, vol. 2, pp. 1-11, 2017.

[10] W. S. Aji and B. Arifitama, "Perancangan Aplikasi Augmented Reality Pengenalan Kendaraan Militer Dengan Metode Marker Based Tracking," in Seminar Nasional Mahasiswa Ilmu Komputer dan Aplikasinya (SENAMIKA), Jakarta, 2020.

[11] N. H. Widayaningsih and H. Handriyotopo, "Perancangan Augmented Reality Berbasis Android Sebagai Promosi Taman Sriwedari Surakarta," CITRAWIRA : Journal of Advertising and Visual Communication, vol. 1, no. 2, pp. 1-22, 2020.

[12] B. A. Pramono, "Desain dan Implementasi Augmented Reality Berbasis Web Pada Aplikasi Furniture Shopping Manager Sebagai Alat Bantu Belanja Online," JURNAL TRANSFORMATIKA, vol. 10, no. 1, pp. 26-33, 2012.

[13] K. S. Wibowo, Fauziah and I. D. Sholihati, "Augmented Reality Dalam Visualisasi Katalog Penjualan Toko Aneka Furniture Berbasis Android Menggunakan Algoritma Fast Corner Detection," Jurnal Teknik Informatika dan Sistem Informasi, vol. 8, no. 3, pp. 1336-1351, 2021.

[14] P. A. Mahardika, I. M. A. Suyadnya and K. O. Saputra, "Rancang Bangun Aplikasi Simulasi Dekorasi Ruangan dengan Memanfaatkan Teknologi Markerless Augmented Reality," J-COSINE, vol. 3, no. 1, pp. 82-90, 2019.

[15] T. Arifianto , "Perancangan Aplikasi Furniture Home Design 3D Dengan Menerapkan Teknologi Augmented Reality Berbasis Android," Jurnal Insand Comtech, vol. 2, no. 1, pp. 15-20, 2017.

[16] A. Junaidi, R. Prabowo, A. Syarif and Y. Fazri, "Implementasi Augmented Reality Furniture Dengan User-Defined Target Berbasis Android," Jurnal Sistem Informasi Bisnis, vol. 10, no. 1, pp. 64-72, 2020. 